\title{
dibujarse en el mundo
}

Luís M. Mansilla

Luís Moreno Mansilla (Madrid 1959, Barcelona 2012) se tituló como arquitecto en 1982 por la E.T.S.A.Madrid, donde ejerció En 1992 fundó con Emilio Tuñón MANSILLA+TUÑÓN arquitectos, un despacho dedicado a la confrontacion de la mente galardonada con diversos reconocimientos destacando el Premio Mies van der Rohe (2007) el Premio Nacional de ArquiEste texto reproduce la ponencia realizada por Luís M. Mansilla en el Simposio Internacional "La formación del arquitecto", que tuvo lugar en el Colegio de Arquitectos de Catalunya en abril de 2005. (Fuente: La formació de l'arqu
Catalunya, ISSN 1133-8849). práctica academica con la actividad proyectual y constructiva.

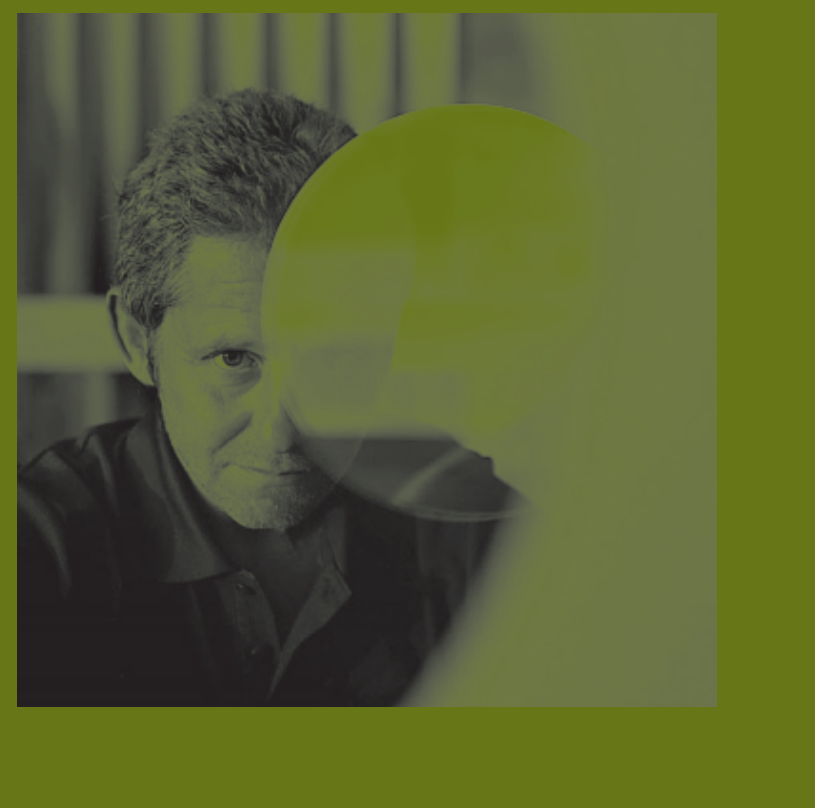

1. Un territorio en transformación

El territorio de la arquitectura continúa sufriendo alteraciones, sus fronteras cambiantes adoptan nuevos perfiles, chocan con quizás se retiran de otros. Lo único cierto es que su "terreno de juego" ya no es el mismo.

Como un impulso que siempre se equilibra, la mirada vuelta hacia la naturaleza se produce en un momento en que la tecnología invade nuestra vida cotidiana. Y así, la arquitectura, que hasta hace poco se ocupaba esencialmente de los fenómenos naturales estáticos o cíclicos -la vistas, el soleamiento, el clima- descubre de la mano de la tecnología la otra cara de la naturaleza aquello que se modifica y cambia, lo inesperado, su constante
movimiento. Y la mirada se dirige no hacia su previsible terquedad, sino hacia su fascinante capacidad de sorprendernos.

Queda entonces una naturaleza por respetar y admirar, pero el precio a pagar es su lejanía. Así que nos encaminamos hacia otra naturaleza artificial, no ya aquella segunda que inventó Leonardo cuando hablaba del arte -esto es, al fin, de la cultura- sino quizás delo, o mejor aún, cuya estructura será la naturaleza, porque es lo único inagotable, aquello que inunda la totalidad de los sentidos. paciones: un mundo esencialmente no visual, sino multisensorial, envolvente. Lo importante ya no serán los espacios, sino los ambientes, empujados por la formidable pujanza de la tecnología, la ansiedad de seguir transformando una naturaleza que no podemos tocar, recreandola, y la escondida y vana esperanza de conurar asi el lacerante paso del tiempo. Un mundo ni mejor ni peor, convertir las nuevas preocupaciones en nuevas oportunidades. Un mundo donde el espacio es ya solo un pequeño fragmento de los ambientes, dibujados con el oído, el tacto, el gusto, la sensaciones son tan plenas como lo son en la naturaleza, porque están presididas no tanto por el cambio como por la sorprendente presencia de lo posible. Explorar este territorio en continuo cambio será sin duda una de las tareas de la arquitectura en los próximos años

En el interior de este escenario resulta difícil orientar la enseñanza como algo vinculado a los contenidos, no solo en permanente movimiento, sino sobre todo en constante transformación. Nos guste o no, aquellas obras de arquitectura por las que mostramos respeto bien podría decirse que sólo tienen algo en común: su capacidad de invención, o de transformación, de la realidad o podría ser: ¿cómo preparar a alguien para hacer lo que todavía podria ser. ¿cómo preparar a alguien para hacer lo que todavía

\section{La otra naturaleza}

La enseñanza de la arquitectura (y también una obra de arquitectura) debería configurar un territorio, un paisaje conceptual y material, donde se multipliquen las oportunidades de que se manifiesten, de que se hagan visibles o presentes aquellas contrabajo del arquitecto.

Y ese trabajo posible y necesario es, digámoslo rápido, la construcción de una segunda naturaleza. Una naturaleza que nos pro(condición existencial).

Es decir, se distinguen aquí dos vectores complementarios; uno es la determinación de una segunda naturaleza; el otro es la vinculación que existe entre la segunda naturaleza y la primera, que representa una

No queda aquí dicho que esta segunda condición sea imprescindible, y sin embargo es, en nuestra modesta opinión, la única co detar de coherencia al conjunto de una obra en un mundo que se ensancha, cuyo espacio se dilata y se hace más complejo, mediante la búsqueda de una precepción global, con todos los sentidos, que se modifica en el tiempo. Y en este nuevo territorio se solapa con la sociedad en lugares nuevos, y erosiona el
encuentro entre lo personal y lo colectivo. Identificar esos nuevos territorios y su roce con la sociedad puede ayudarnos a orientar hacia dónde debe magnetizarse la mirada sobre el mundo, hacia
dónde caminar mientras intentamos aprender a ser arquitectos.

\section{La arquitectura como modo de conocimiento}

Llegados a este punto, cualquier lector atento habrá observado que ya aquí se han dado muchas cosas por supuestas, y sin embargo quizás no lo sean. La primera de ellas, y tal vez la más arquitectura y, dentro de estas formas colectivas, muchas formas personales de imaginarla. sarian alcanza a la sociedad, y por tanto, dibujan un vecto los intereses de la arquitectura y tratan de imbricarse en aquellas cuestiones que dan forma a la sociedad en movimiento. Ahora cuestiones que dan forma a la sociedad en movimiento. Ahora
bien, en el interior de esta cuestión, los vectores personales se mueven a interior de esta cuestión, los vectores personales se nan con los colectivos: una atenta mirada, casi únicamente a nan con los colectivos: una atenta mirada, casi únicamente a estructuras de textos, nos podría acercar a diversos modos de entendimiento de la arquitectura: como forma de vida, como conocimiento, como función existencial, como modo de actividad...
Que nadie se asuste si volvemos hasta Ruskin para explicar esta distinción: Las siete lámparas de la arquitectura (1849) inician una vereda perfumada de contenido religioso en la que sin embargo está presente esa condición de extrañamiento que el título conlleva; la arquitectura es iluminada por algo ajeno a uno mismo, por unas luces a medias prendidas por la historia y una poderosa concepción cristiana del mundo; no hay distinción entre la forma de hacer arquitectura y la forma de ser uno mismo; es la arquitectura como forma de vida o, mejor aún, como doctrina de la vida. Y lo es porque construir es una forma particular es la manifestación del trabajo, la arquitectura es la manifestación cia la vida. La verdad de la infraestructura, el vigor de la inteligenvibración, el recuerdo como responsabilidad con el futuro o la obediencia como forma de organizar el trabajo serán los aires que envuelven la mirada de un Ruskin moralista incómodo ante la poética que Viollet-le-Duc ya intuye agazapada entre las técnicas. Un modo de ver la arquitectura muy distinta a la del movimiento moderno: casi cincuenta años han transcurrido cuando Le Corbusier escribe Les 5 points d'une architecture nouvelle. Los artículos ("Las siete lámparas...", "Los cinco puntos...") están hablando, con su determinación, de una misma certeza que sobrevuela ambos escritos, pero ya no existe esa condición externa que presidía los textos de Ruskin: la arquitectura no es iluminada por virtudes, sino que se basa en principios. Le Corbuiser no comete el error de Ruskin de refrendar argumentaciones de tipo que establece principios, los inicios de un camino a seguir, mediante reglas: reglas que son la transcripción en esa época de
una forma de hacer, cuya mayor aportación es ser consecuencia (al menos en teoría) de lo que transcurre, del avance de la técnica. Su forma de imaginar el mundo de la arquitectura se asemeja a las matemáticas: una suma puede parecernos innecesaria, pero podemos con facilidad detectar si es correcta o no cuando conozcamos las reglas. Es un invento gigantesco, coherente, pero invento del hombre al fin y al cabo. Algunas variables quedan despejadas, y las ecuaciones tienen solución. Una vez dentro, las reglas no pueden ser ignoradas. La arquitectura de Le Corbusier está llena de demostraciones sorprendentes y elegantes de sus creación de un modelo, limitado, que ayuda a la arquitectura a desarrollarse, como las matemáticas ayudan a conocer el mundo, aunque el mundo no sea las matemáticas.

Nuestra mirada continúa esa tradición de la arquitectura como modo de conocimiento del mundo, en el que voluntariamente se desdibujan las fronteras entre hacer arquitectura y aprender a hacer arquitectura. Se trata de un proceso continuo, en el que aparece en primer plano que el trabajo de arquitectura mejora las cosas, y que estos vínculos adquieren su sentido en cuanto sombras de un modo de entender la relación con aquella primera y lo social encuentran un territorio común, un ámbito de participación. Y la única forma de participar es la transformación. La actividad de los hombres, una aportación personal a la transfor-
Los modos colectivos requieren de una extensión que necede vivir iluminada por las mismas virtudes que la vida: sacrificio, recuerdo, verdad, obediencia...igual que para Ruskin el sacrificio moral con la experiencia, disociando método y contenido, sino cuanto más se refuerzan los vínculos o correspondencias entre arquitectura es pues, en términos vitales, como cualquier otra
La percepción de la capacidad de los objetos o la materia, en su forma de ser ordenada, para establecer un vínculo entre nuestra quizás lo único imprescindible que hay que descubrir.

4. Los proyectos son las sombras de las ideas

De este modo, los proyectos de arquitectura son como la sombra de un cuerpo -de una idea- que toma la forma del terreno contra el que se estrella y el aire de la luz que la dibuja; e la vida- son infinitas. Como ocurre también en la arquitectura, importante es la forma que toman las cosas, una forma que haga presente la diversidad y la libertad que da sentido a nuestras presente la diversidad y la libertad que da sentido a nuestras
acciones, porque son aquello que dilata nuestro mundo personal
para acercarlo a los demás.

La consideración de la arquitectura como algo que trasciende la mera resolución de un problema técnico y hace presente un modo de relación con la cultura y la naturaleza que, aunque personal, tiene siempre una cierta vocación de universalidad, es la pista que nos conduce a conocer que en la profesión hay muchos modos de entendimiento, pero una vez que se escoge uno existen unas leyes determinadas. Descubrir la existencia de estas reglas es conocer que existe una relación precisa entre todos los

La capacidad de establecer vínculos entre las cosas y las ideas aparece así como el núcleo no solo del trabajo del arquitecto, sino también del modo de acercarse a la arquitectura, moviéndose en vectores de espacio y tiempo, y estableciendo relaciones entre ellos. Un vector espacial, entre el yo y los otros, y un vector temporal, entre el pasado y el futuro, dibujan en mi opinión
el territorio de la arquitectura como el de su aprendizaje.

El acercamiento a la arquitectura se articula así entre estos cuatro territorios, que en su grado de abstracción pueden tomar todavía cualquier forma. De hecho, éste es el trabajo interesante: ver la forma que adoptan las ideas, y no las ideas en sí mismas ni las formas en si mismas. Un terreno de juego, de aprendizaje sobre el que cada uno va a dibujar una gráfica de relaciones que brevuela el lugar, los materiales, las funciones: estas necesidades son precisamente aquello que va a dar forma a las cosas, y en cada momento harán distintas las sombras de una idea de ser nosotros ante el mundo.

De este modo, nuestro mirar intuye que el objeto del hombre no es la contemplación, sino la producción, y que por tanto la mirada no tiene un talante estético y estático, sino que es un mirada no tiene un talante estético y estático, sino que es un
arranque de la transformación del mundo. Y la mirada-acción adquiere todo su sentido en cuanto el trabajo es capaz de adquirir al tiempo una condición individual y una condición colectiva. Y ello implica un esfuerzo de generalización, de abstracción, de para hacer sitio a los demás. Olvidar esta categoría sería empequeñecer el mundo de la arquitectura.

Frente a una naturaleza cuyo destino es estar predeterminado la arquitectura se presenta como algo que pertenece al dominio
de la cultura, cuyo marco está por hacer. Hacer arquitectura tiene de la cultura, cuyo marco está por hacer. Hacer arquitectura tiene que ver, por tanto, con determinar aquello que está indetermina-
do, que pertenece todavía al mundo de las ideas. Nuestro trado, que pertenece todavía al mundo de las ideas. Nuestro trabajo consiste en convertir esas ideas en cosas, y situarlas en un mundo más material, dibujando el proyecto como un intercambio
entre subjetividad y sistema, entro lo arbitrario y lo posible.

\section{Un trasiego entre cosas e ideas}

La arquitectura es un conjunto de ideas nebulosas, anteriores a la propia presencia de las necesidades o del lugar, que toman forma, contra las asperezas del lugar y las obsesiones de los clientes. Ése es el momento definitivo, tanto de la crítica como de la arquitectura: el momento en que las cosas toman forma. Por lo tanto, e nudo central de lo arquitectónico es algo que sobrevuela lo concreto y pertenece, necesariamente, al dominio de lo abstracto.

Ahora bien, ¿cómo devienen formas las cosas?... Se trata más bien de un proceso de descomposición de las partes, que continúa en una recomposición hipotética de las mismas. Esto quiere decir que los proyectos son como un trozo de vida, y que en su tornos. Como el jardín de senderos que se bifurcan, los distintos aspectos del proyecto se aferran a su compañía y se echan a aspectos del proyecto se aferran a su compania y se echan a una sola idea, pues solo se puede compartir aquello que no está ocupado por la omnipresencia de las ideas; en realidad, sólo es habitable el espacio entre ellas).

En este proceso de formación, cada uno toma, pues, su camino: la estructura adquiere un carácter específico, la planta empieza a deshilacharse a partir de un objeto, los materiales empiezan a enfocarse a partir del recuerdo. O de cualquier otra cosa. Eso no importa. Lo que de verdad importa es el trasiego entre las cosas y las ideas. Un trasiego continuo desde las ideas que se emparentan con formas a las formas que sugieren ideas. Cuando han avanzado en sus caminos, el proyecto llega a su punto de crisis, es decir, a un punto en el que lo hecho interesa tanto como lo que está por descubrir; en

Y el proyecto -esto es definitivo- empieza a alimentarse de sus propias exigencias y necesidades. Es el tiempo en que lo que había vivido con independencia debe acercarse. el proyecto debe tomar su distancia para que las cosas se enfoquen. Encontrar un punto exacto desde el que todas las figuras adquieren un único perfil, una forma de expresión en la que, a pesar de estar presentes, de algún modo desaparecen. Proyectar es ocultar lo propio, hacer invisibles las ideas, para dejar espacio a los demás. Es un proceso de respiración, de ida y vuelta, de expansión; luego llega el momento de simplificar e intensificar. Y la forma se hace destino entonces, una vez que se decide la resolución particular de los posibles. Y de este modo un proyecto se convierte, ante todo, en su forma de expresión. De expresión de uno mismo. 